\title{
Clinical features and outcomes of germline mutation BRCA1-linked versus sporadic ovarian cancer patients
}

\author{
Agnieszka Synowiec ${ }^{1 *}$ (D), Gabriel Wcisło ${ }^{1}$, Lubomir Bodnar ${ }^{1}$, Bohdan Górski ${ }^{2}$, Jolanta Szenajch', \\ Katarzyna Szarlej-Wcisło ${ }^{1}$ and Cezary Szczylik ${ }^{1}$
}

\begin{abstract}
Background: The role of germline mutations in BRCA1 and BRCA2 genes in the risk of the development of ovarian cancer is clinically well established. BRCA1/2 testing seems to have increasing role in clinical management in patients with advanced ovarian cancer who require treatment with poly(ADP-ribose) polymerase inhibitors.

Methods: Between 2002 - 2008, 125 consecutive patients with ovarian cancer were categorized as having three founder mutations in the BRCA1 gene in Poland as: 5382insC [exon 20], 4153delA [exon 11.17], and $300 \mathrm{~T}>\mathrm{G}$ [exon 5]. PFS (progression free survival) and OS (overall survival) were determined by Kaplan-Meier analysis with log rank test, univariate comparisons, and multivariate regression analysis using Cox proportional hazards model.

Results: Of the 125 patients, the founder mutations of BRCA1 were reported in 17 patients (13.6\%). The median OS was longer for BRCA mutated patients (not reached vs 35.6 months, $p=0.041$ ). PFS was similar for both kinds of ovarian cancer. In multivariate analysis, age $\geq 70$ years, suboptimal surgery, and BRCA1 wild type were poor prognostic factors. The BRCA1 mutation reduced the likelihood of death in ovarian cancer by $86 \%$ (HR 0.14; Cl: 0.032-0.650, $p=0.012$ ).

Conclusion: In conclusion, we found better overall survival for ovarian cancer patients with BRCA1 germline mutations in comparison with patients without these mutations (sporadic) ovarian cancer. Thus, BRCA1 germline mutations appear to be an independent prognostic factor for ovarian cancer.
\end{abstract}

Keywords: Germline mutations of BRCA1, Ovarian cancer, Chemotherapy, Survival

\section{Introduction}

Ovarian cancer is the leading cause of death in women from gynecological malignant diseases. The lifetime probability of ovarian cancer in the general population is approximately $1.6 \%$. This risk increases to $5 \%$ for women with one first-degree relative with ovarian cancer and to $7.2 \%$ for women with two or three relatives with ovarian cancer [1].

$B R C A 1$ and $B R C A 2$ genes are high-penetrating with important roles during tumorigenesis. Both genes encode proteins that interact with a machinery of recombination of DNA or DNA repair pathways [2]. Twenty percent of breast cancer has familial basis and approximately $5 \%$ to

\footnotetext{
* Correspondence: asynowiec@wim.mil.pl

'Department of Oncology, Military Institute of Medicine, 128 Szaserow Str., 04-141 Warsaw, Poland

Full list of author information is available at the end of the article
}

$10 \%$ of breast cancer is hereditary. Two-thirds of these hereditary cancers occur in carriers with mutations of $B R C A 1$ or BRCA2 which are germline mutations [3]. Some preclinical studies have shown that $B R C A 1$ appears to be an important responding factor to both DNAdamaging (platimun-compounds) and taxane-based chemotherapy [4]. Molecularly, these anticancer agents are to be as crucial modulators of $B R C A$-dependent pathways, independently of detected $B R C A 1 / 2$ mutations defined germline or sporadic [5].

The BRCAness phenotype may be a result of defective homologous recombination related to several mechanisms, including epigenetic hypermethylation of the $B R C A 1$ promoter, somatic mutation of $B R C A 1 / 2$, or loss of function mutations in other homologous recombination orchestrating molecules. The complex profile of the $B R C A$ ness phenotype correlates with responsiveness 
to platinum and poly-ADP ribose polymerase (PARP) inhibitors [6]. On the other hand, there have been known at least, two molecular mechanisms responsible for chemotherapy resistance and recurrence of ovarian cancer such as 1 .secondary mutations restoring BRCA1/2, and 2.high levels of PARP, Fanconi anemia proteins and P53 [7, 8]. Determination of the BRCA1/2 status may be a relevant clinical biomarker both for survival prognosis and prediction both for response or resistance to chemotherapy in sporadic ovarian cancer $[9,10]$.

$B R C A$ mutations may have impact on better survival of patients with ovarian cancer when compared with those without mutations. Several studies have investigated the possible effects of $B R C A 1$ mutation on clinical and pathologic characteristics defined by earlier age of onset in any mutation carriers with the possible better response to platinum-based chemotherapy, but results of these studies were inconclusive. Some of these studies have demonstrated longer survival in epithelial invasive ovarian cancer patients $[11,12]$ who are $B R C A 1$ mutation carriers in comparison with noncarriers, but other investigators did not find a survival benefit in $B R C A 1$ mutation carriers [13-15]. Recently reported results have revealed that after 3 years since the ovarian cancer diagnosis, the presence of a $B R C A 1$ or $B R C A 2$ mutation was associated with a clinically better prognosis (HR 0.68; 95 \% CI: $0.48-0.98, p=0.03$ ), which has not been sustained 10 years after the diagnosis of ovarian cancer (HR 1.00; 95 \% CI: 0.83-1.22, $p=0.90)[16,17]$.

The aim of our study was to assess clinical features and treatment outcomes in ovarian cancer patients, having a founder mutation in BRCA1 gene in comparison with clinical results of sporadic ovarian cancer patients.

\section{Patients and methods Patients}

A consecutive series of 125 patients with ovarian cancer diagnosed and treated at the Military Institute of Medicine in Warsaw, Poland, between 2002-2008 was studied. All patients underwent surgery defined as radical, optimal tumor debulking with residual disease < $1 \mathrm{~cm}$, or suboptimal as residual disease $>1 \mathrm{~cm}$. The pathology reports were classified as epithelial ovarian cancer serous, endometrioid, mucinous, clear cell, mixed, or unspecified. Chemotherapy was used in all patients. Mutation analysis was performed in all enrolled patients. The study protocol was approved by the local Ethics Committee (The Resolution of The Bioethics Committee of Military Institute of Medicine at Warsaw, No $48 /$ WIM/2008 data November, $19^{\text {th }}$ 2008), and written informed consent was obtained from all participants of the study.

\section{Chemotherapy regimen}

The first line chemotherapy consisted of 6 courses. The first version of chemotherapy regimen consisted of $135 \mathrm{mg} / \mathrm{m}^{2}$ of intravenous infusion paclitaxel over 24-h on day 1 followed by $75 \mathrm{mg} / \mathrm{m}^{2}$ of intravenous infusion cisplatin on day 2. The second version of chemotherapy regimen consisted of $175 \mathrm{mg} / \mathrm{m}^{2}$ of intravenous infusion paclitaxel over 3-h on day 1 followed by AUC6 according to Calvert formula of intravenous 30-min infusion carboplatin on day 2. Standard premedication (dexamethasone $20 \mathrm{mg}$, ranitidinum $50 \mathrm{mg}$, clemastinum $2 \mathrm{mg}$ ) was given intravenously to prevent hypersensitivity reaction to paclitaxel. Treatments were administered every 3 weeks. The third version of chemotherapy was based upon carboplatin AUC5 according to Calvert formula of intravenous 30min infusion. The fourth version of treatment was given as neoadjuvant triple chemotherapy regimen based upon paclitaxel (175 mg/m $\mathrm{m}^{2}$ over 3-h intravenously), carboplatin (AUC5 intravenously), and caelyx $\left(20 \mathrm{mg} / \mathrm{m}^{2}\right.$ intravenously) or epirubicin (50 mg/m ${ }^{2}$ intravenously) which was administered for three courses before debulking surgery with further continuation of standard chemotherapy with paclitaxel and carboplatin in mentioned doses up to total number of six courses. The fifth version of chemotherapy was a regimen based upon combination of gemcitabine (1000 mg/m $\mathrm{m}^{2}$ intravenously on days 1,8 every 21 days) and cisplatin ( $75 \mathrm{mg} / \mathrm{m}^{2}$ intravenously on day 1 every 21 days) given as the primary chemotherapy as well.

\section{Mutational analysis}

High-molecular-weight DNA was isolated from peripheral blood leukocytes by nonenzymatic and rapid method described by Lahiri and Nurnberger [18]. Mutation analysis was performed for three common in Poland founder mutations in BRCA1 (5382insC - exon 20; 4153delA - exon 11.17) by a multiplex allele-specific polymerase chain reaction (PCR) assay. $300 \mathrm{~T}>\mathrm{G}-$ exon 5 mutation generates a novel restriction enzyme site. This mutation can be detected after digesting amplified DNA with Ava II. To show the different BRCA1 alleles, the PCR products were subjected to horizontal electrophoresis in a $2.0 \%$ agarose gel and stained with ethidium bromide. We analyzed samples of all enrolled patients [19].

\section{Statistical analysis}

Demographic data are shown as median or mean with standard deviation (SD) and $95 \%$ confidence interval (CI). Relationships between categorical variables were assessed using the Chi-square test, Yates-corrected Chisquare test or Mann-Whitney $U$ test. Progression-free survival (PFS) was calculated from the start date of chemotherapy to the first evidence of treatment failure. Overall survival (OS) was defined as the time interval 
between the date of starting chemotherapy to death of any cause. PFS and OS were estimated using the Kaplan-Meier methods and differences in survival were compared by using log-rank test. On univariate comparisons of survival between groups, statistical significance was assessed using the Cox-Mantel test. Multivariate regression analyses were performed using the Cox proportional hazards model. A $p$ value of $<0.05$ was considered statistically significant. For calculations we used STATISTICA for Windows Version 7.0 software.

\section{Results}

\section{Patient characteristics}

The study population involved a series of 125 consecutive patients with ovarian cancer treated primary surgically and further chemotherapeutically. Table 1 shows patient characteristics. The patients' age ranged from 28 to 85 years (median, 55 years). Most patients were in advanced stage ovarian cancer (III and IV stages, 101/125: $80.8 \%$ ). More than half of patients were diagnosed pathologically with serous ovarian cancer. Standard chemotherapy was given to participated patients in this study with exception of one patient received gemcitabine combined with cisplatin as the primary chemotherapy.

Three founder mutations (5382insC - exon 20; 4153delA - exon 11.17; $300 \mathrm{~T}>\mathrm{G}$ - exon 5) dominating in Poland were tested. Founder mutations of the BRCA1 gene were noted with the rate of $13.6 \%$. The most frequent $(9.6 \%)$ mutation was in exon 20 (5382insC). Table 2 shows the comparative distribution of founder mutations of BRCA1 in ovarian cancer patients.

Table 3 presents clinical and pathological ovarian cancer characteristics with the BRCA1 gene status. Younger patients with ovarian cancer were seen among $B R C A 1$ mutation carriers in comparison with noncarriers (median age 47 vs 56 , respectively, $p=0.004$ ).

\section{Progression free survival analysis incorporated the status of the BRCA1 gene and other clinical variables}

On univariate analysis for PFS, patients with advanced stage, serous histology, nonoptimal debulking surgery with residual tumor $>1 \mathrm{~cm}$, and without paclitaxel in the chemotherapy regimen correlated with worse PFS. BRCA1 gene status was not a significant factor for PFS. Detailed results of univariate and multivariate analyses are shown in Table 4. The FIGO stage, serous histology, optimal debulking surgery, and chemotherapy with paclitaxel combined with platinum compound were significant prognostic factors for PFS. The status of BRCA1 was not of clinical value as prognostic factor after using multivariate analysis for PFS.
Table 1 Patient characteristics

\begin{tabular}{|c|c|}
\hline Number of patients & $n=125$ \\
\hline Median (range) age at diagnosis in years & $55(28-85)$ \\
\hline \multicolumn{2}{|l|}{ Performance status WHO: } \\
\hline .0 & $15.2 \%(19 / 125)$ \\
\hline$\cdot 1$ & $77.6 \%(97 / 125)$ \\
\hline$\cdot 2$ & $7.2 \%(9 / 125)$ \\
\hline $\mathrm{BSA}\left(\mathrm{m}^{2}\right)$ & $1.69\left(95 \% \mathrm{Cl}^{\prime} 1.65-1.72\right)$ \\
\hline \multicolumn{2}{|l|}{ FIGO stage: } \\
\hline$\cdot 1$ & $11.2 \%(14 / 125)$ \\
\hline$\cdot \|$ & $8.0 \%(10 / 125)$ \\
\hline$\cdot \| A$ & $5.6 \%(7 / 125)$ \\
\hline$\cdot \| \mathrm{B}$ & $7.2 \%(9 / 125)$ \\
\hline$\cdot \| C$ & $56.0 \%(70 / 125)$ \\
\hline$\cdot \operatorname{IV}$ & $12.0 \%(15 / 125)$ \\
\hline \multicolumn{2}{|l|}{ Chemotherapy regimen: } \\
\hline - Paclitaxel/cisplatin & $43.2 \%(54 / 125)$ \\
\hline - Paclitaxel/carboplatin/ caelyx & $8.8 \%(11 / 125)$ \\
\hline - Paclitaxel/carboplatin & $36.8 \%(46 / 125)$ \\
\hline - Carboplatin & $8.8 \%(11 / 125)$ \\
\hline - Paclitaxel/carboplatin/epirubicin & $1.6 \%(2 / 125)$ \\
\hline - Gemcitabine/ cisplatin & $0.8 \%(1 / 125)$ \\
\hline \multicolumn{2}{|l|}{ Type of histology: } \\
\hline - Serous & $54.4 \%(68 / 125)$ \\
\hline - Endometrioid & $26.4 \%(33 / 125)$ \\
\hline - Mucinous & $7.2 \%(9 / 125)$ \\
\hline - Clear cell & $4.0 \%(5 / 125)$ \\
\hline - Mixed & $2.4 \%(3 / 125)$ \\
\hline - Unspecified & $5.6 \%(7 / 125)$ \\
\hline \multicolumn{2}{|l|}{ Grading: } \\
\hline$\cdot 1$ & $3.2 \%(4 / 125)$ \\
\hline$\cdot 2$ & $32.8 \%(41 / 125)$ \\
\hline$\cdot 3$ & $23.2 \%(29 / 125)$ \\
\hline - Unspecified & $40.8 \%(51 / 125)$ \\
\hline \multicolumn{2}{|l|}{ Primary surgery: } \\
\hline - Radical & $19.2 \%(24 / 125)$ \\
\hline - Optimal (<1 cm) & $42.4 \%(53 / 125)$ \\
\hline - Suboptimal (>1 cm) & $38.4 \%(48 / 125)$ \\
\hline
\end{tabular}

Table 2 Distribution of founder mutations of the BRCA1 gene in ovarian cancer patient

\begin{tabular}{ll}
\hline Germline mutation & All ovarian cancer $(n=125)$ \\
\hline 5382insC [exon 20] & $12 / 125(9.6 \%)$ \\
$300 \mathrm{~T}>\mathrm{G}$ [exon 5] & $3 / 125(2.4 \%)$ \\
4153 delA [exon 11.17] & $2 / 125(1.6 \%)$ \\
All mutations & $17 / 125(13.6 \%)$ \\
\hline
\end{tabular}


Table 3 Clinical and pathological ovarian cancer characteristics determined by the BRCA1 gene status

\begin{tabular}{|c|c|c|c|c|}
\hline Status BRCA1 & $\begin{array}{l}\text { Wild type } \\
(n=108)\end{array}$ & $\begin{array}{l}\text { Germline } \\
\text { mutation } \\
(n=17)\end{array}$ & Statistics & $p$ value \\
\hline $\begin{array}{l}\text { Median (range) age at } \\
\text { diagnosis in years }\end{array}$ & $56(28-85)$ & $47(39-70)$ & $-2.859^{a}$ & 0.004 \\
\hline \multicolumn{5}{|l|}{ Performance status WHO: } \\
\hline$\cdot 0$ & 15 & 4 & & \\
\hline - Other & 93 & 13 & $0.44^{\mathrm{b}}$ & 0.51 \\
\hline \multicolumn{5}{|l|}{ FIGO stage: } \\
\hline - Early $(I, I I)$ & 22 & 3 & & \\
\hline - Advanced (III,IV) & 86 & 14 & $0.07^{b}$ & 0.95 \\
\hline \multicolumn{5}{|l|}{ Chemotherapy regimen: } \\
\hline - With paclitaxel & 97 & 16 & & \\
\hline - Without paclitaxel & 11 & 1 & $0.01^{b}$ & 0.91 \\
\hline \multicolumn{5}{|l|}{ Chemotherapy regimen: } \\
\hline - With cisplatin & 47 & 8 & & \\
\hline - With carboplatin & 61 & 9 & $0.1^{c}$ & 0.75 \\
\hline \multicolumn{5}{|l|}{ Type of histology: } \\
\hline - Serous & 57 & 11 & & \\
\hline - Other & 51 & 6 & $0.84^{c}$ & 0.36 \\
\hline \multicolumn{5}{|l|}{ Grading: } \\
\hline - 1 and 2 & 38 & 7 & & \\
\hline - 3 and unspecified & 70 & 10 & $0.23^{c}$ & 0.63 \\
\hline \multicolumn{5}{|l|}{ Primary surgery: } \\
\hline - Optimal (<1 cm) & 68 & 9 & & \\
\hline - Suboptimal (>1 cm) & 40 & 8 & $0.62^{c}$ & 0.43 \\
\hline
\end{tabular}

${ }^{a}$ Mann-Whitney $U$ test

bYates-corrected Chi-square test

${ }^{\mathrm{C} C h i-s q u a r e ~ t e s t ~}$

\section{Overall survival analysis incorporated the status of the} BRCA1 gene and other clinical variables

On univariate analysis for OS (Table 5), we show that age at ovarian cancer onset $\geq 70$ years, advanced stage, serous histology, suboptimal surgery, and use of chemotherapy regimen without paclitaxel are related to shorter OS. Interestingly, BRCA1 status appeared to be of clinical value as a prognostic factor for OS in ovarian cancer patients. Carriers of any mutation of the BRCA1 gene with ovarian cancer had better survival at two years in comparison with noncarriers. Figure 1 presents OS in patients with ovarian cancer stratified by $B R C A 1$ status with median not reached in carriers of $B R C A 1$ mutations vs median of 35.6 months for noncarriers $(p=0.041)$. In multivariate analysis (Table 5), age $\geq$ 70 years, suboptimal surgery and expression of wild type of the $B R C A 1$ gene correlate with poor prognosis for OS. BRCA1 germline mutations reduced by $86 \%$ likelihood of death in our ovarian cancer patients (HR 0.14 [CI: 0.032-0.650], $p=0.012$ ).

\section{Discussion}

Our results found the total rate of $B R C A 1$ mutations was $13.6 \%$ in 125 ovarian cancer patients. This result is in accordance with other previously published studies in the Polish population with germline mutations in BRCA1 and $B R C A 2$ in $13.5 \%$ and $13.9 \%$ of patients, respectively $[20,21]$. We also show that BRCA1 germline mutations are associated with good prognosis for patients with ovarian cancer and OS was better for carriers of BRCA1 mutations (HR 0.14, 95 \% CI: 0.032-0.650, $p=0.012$ ) than for noncarriers. This observation is in accordance with results of other authors, for example, Rubin et al. [22] for the first time determined that ovarian cancer associated with BRCA1 mutations had a more favorable clinical course, and it was confirmed by other studies in which this advantage in survival of mutation carriers was reported to be an independent protective factor [23].

Here we report that PFS assessed both on univariate and on multivariate analyses (BRCA1 mutations vs $B R C A 1$ wild type, median 21.5 months vs 14.6 months, $p=0.58$, respectively) show a slight favor with predictive value for patients with mutated $B R C A 1$ but without statistical significance. We present that FIGO stage, serous histologic type, primary debulking surgery and chemotherapy based upon combination of platinum compound with paclitaxel, are typical clinical variables that correlate with PFS. Among 71 Jewish patients with ovarian cancer, 22 had BRCA1 three germline mutations and one truncating mutation, and 12 had BRCA2 truncating mutations vs 37 patients with sporadic ovarian cancer. Overall survival was improved in patients with mutated forms of $B R C A$ in comparison with sporadic ovarian cancer patients (91 months vs 54 months, respectively; $p=0.046)$. In accordance with our results, the authors showed that patients with $B R C A$ mutations had slightly longer disease free survival but not statistically significant (49 months vs 19 months, respectively; $p=0.16$ ) [24]. Tan et al. [25] coined the term of a clinical syndrome of BRCAness which relies on better prognosis for response rate after first- line chemotherapy and at subsequent recurrences, overall survival, serous histology (but not necessary), and TFI (treatment-free interval defined as the time between each line of treatment calculated from the date of the last course of the previous chemotherapy to the date of the first cycle of the next chemotherapy). In ovarian cancer patients with $B R C A$ mutations the median TFI for three lines of chemotherapy was significantly longer than in sporadic ovarian cancer patients (first-line, $p<0.001$; second-line, $p<0.015$; thirdline, $p=0.002$, respectively). The median overall survival for $B R C A$-positive ovarian cancer patients was better than in controls (from the time of diagnosis 8.4 years vs 2.9 years, respectively; $p<0.002$ ) [25, 26]. Gallagher et al. [27] reported in a group of 110 patients (36 with three 
Table 4 Univariate and multivariate analyses for PFS of ovarian cancer

\begin{tabular}{|c|c|c|c|}
\hline \multicolumn{4}{|l|}{ Univariate analysis } \\
\hline Variable & n (\%) & Median (months) & $p$ value \\
\hline \multicolumn{4}{|l|}{ Age: } \\
\hline$<70$ & 118 (94.4 \%) & 10.4 & \multirow[t]{2}{*}{0.51} \\
\hline$\geq 70$ & 7 (5.6 \%) & 16.0 & \\
\hline \multicolumn{4}{|l|}{ Performance status WHO: } \\
\hline$\cdot 0$ & 19 (15.2\%) & 14.7 & \multirow[t]{2}{*}{0.06} \\
\hline - Other & $106(84.8)$ & 21.4 & \\
\hline \multicolumn{4}{|l|}{ FIGO stage: } \\
\hline - Early $(I, I)$ & $24(19.2 \%)$ & NR & \multirow[t]{2}{*}{$<0.001$} \\
\hline - Advanced (III, IV) & $101(80.8 \%)$ & 13.4 & \\
\hline \multicolumn{4}{|l|}{ Chemotherapy regimen: } \\
\hline - With paclitaxel & 113 (90.4 \%) & 16.8 & \multirow[t]{2}{*}{0.032} \\
\hline - Without paclitaxel & $12(9.6 \%)$ & 10.3 & \\
\hline \multicolumn{4}{|l|}{ Chemotherapy regimen: } \\
\hline - With cisplatin & 55 (44.0\%) & 23.0 & \multirow[t]{2}{*}{0.24} \\
\hline - With carboplatin & $70(56.0 \%)$ & 13.5 & \\
\hline \multicolumn{4}{|l|}{ Type of histology: } \\
\hline - Serous & $68(54.4 \%)$ & 13.2 & \multirow[t]{2}{*}{$<0.001$} \\
\hline - Other & $57(45.6 \%)$ & 34.8 & \\
\hline \multicolumn{4}{|l|}{ Grading: } \\
\hline - 1 and 2 & 45 (36.0 \%) & 16.0 & \multirow[t]{2}{*}{0.40} \\
\hline - 3 and unspecified & $80(64.0 \%)$ & 14.6 & \\
\hline \multicolumn{4}{|l|}{ Primary surgery: } \\
\hline - Optimal (<1 cm) & 77 (61.6\%) & 24.7 & \multirow[t]{2}{*}{$<0.001$} \\
\hline - Suboptimal (>1 cm) & 48 (38.4 \%) & 11.0 & \\
\hline \multicolumn{4}{|l|}{ BRCA1 status: } \\
\hline - Wild type & $108(86.4 \%)$ & 14.6 & \multirow[t]{2}{*}{0.58} \\
\hline - Germline mutation & $17(13.6 \%)$ & 21.5 & \\
\hline \multicolumn{4}{|l|}{ Multivariate analysis } \\
\hline Variable & \multicolumn{2}{|l|}{$\mathrm{HR}(95 \% \mathrm{Cl})$} & $p$ value \\
\hline \multicolumn{4}{|l|}{ FIGO stage: } \\
\hline - Early $(I, I)$ & \multirow{2}{*}{\multicolumn{2}{|c|}{$0.21(0.071-0.634)$}} & \multirow[t]{2}{*}{0.006} \\
\hline - Advanced (III, IV) & & & \\
\hline \multicolumn{4}{|l|}{ Chemotherapy regimen: } \\
\hline - With paclitaxel & \multirow{2}{*}{\multicolumn{2}{|c|}{$0.46(0.242-1.020)$}} & 0.034 \\
\hline - Without paclitaxel & & & \\
\hline Type of histology: & & & \\
\hline - Serous & $0.55(0.318-$ & 916) & 0.027 \\
\hline - Other & & & \\
\hline Primary surgery: & & & \\
\hline - Optimal (<1 cm) & $0.54(0.308-$ & .804) & 0.011 \\
\hline - Suboptimal (>1 cm) & & & \\
\hline
\end{tabular}

Table 4 Univariate and multivariate analyses for PFS of ovarian cancer (Continued)

\begin{tabular}{l}
\hline BRCA1 status: NG NS \\
- Wild type \\
- Germline mutation \\
\hline NG not given, NR not reached, NS statistically not significant
\end{tabular}

germline mutations of $B R C A$ genes (20 BRCA1 mutations, $16 B R C A 2$ mutations) vs 74 controls) that ovarian cancer patients with $B R C A$ mutations had better survival (median not reached vs 67.8 months for controls, respectively; $p=0.02$ ). The multivariate analysis sustained crucial role of $B R C A$ mutations in overall survival prognosis (HR 0.36; $95 \%$ CI 0.14-0.93) but disease-free survival was not significantly different between $B R C A$ mutations and control ovarian cancer patients (median 26.9 months vs 24.0 months, respectively; $p=0.30$ ).

In our study, the age at the onset of ovarian cancer for $B R C A 1$ wild type was almost 10 years postponed than in carriers of BRCA1 mutations (median 56 years vs 47 years, respectively, $p=0.004$ ). Thigpen et al. [28] decided to determine major prognostic factors in 2123 ovarian cancer patients who were studied in the six GOG (Gynecologic Oncology Group) clinical trials. It turned out that only three factors had impact on prognosis for overall survival of the entire investigated population, i.e., age, volume of residual disease, and performance status. Based upon the results of studied patients, elder patients with ovarian cancer ( $>69$ years) had poorer survival. Therefore, age seems to have indirect roles in better survival of patients with mutated BRCA1 through better response to chemotherapy, better tolerance of such a therapy without other health problems which typically are associated with elder patients. But on the other hand, the second-line chemotherapy due to relapsed ovarian cancer could be used in elder patients after detailed assessment of performance status rather than making-decision based primarily on the age [29].

Malignant diseases are the final results of incorrect interactions between immune-surveillance in a healthy organism and unrestricted proliferation of a small portion of cells that constitute a solid tumor or leukemia. The fundamental process that is primarily responsible for tumorigenesis embraces changes in the DNA sequences of the genomes of malignant cells. Recently accumulating knowledge clearly shows that detection cancer genome structural changes at the levels of DNA sequences (mainly somatic mutations) and epigenetic alterations lead to improper functions in cells that constantly become malignant. This dynamic process defines cancer as an evolutionary entity determining highly probabilistic events providing finally advanced malignant disease [30]. Naturally occurring during malignant progression, genome 
Table 5 Univariate and multivariate analyses for OS of ovarian cancer

\begin{tabular}{|c|c|c|c|}
\hline Variable & n (\%) & Median (months) & $p$ value \\
\hline \multicolumn{4}{|l|}{ Age: } \\
\hline$<70$ & $118(94.4 \%)$ & 46.0 & \multirow[t]{2}{*}{0.022} \\
\hline$\geq 70$ & 7 (5.6 \%) & 14.8 & \\
\hline \multicolumn{4}{|l|}{ Performance status WHO: } \\
\hline$\cdot 0$ & 19 (15.2\%) & NR & \multirow[t]{2}{*}{0.28} \\
\hline - Other & $106(84.8)$ & 36.2 & \\
\hline \multicolumn{4}{|l|}{ FIGO stage: } \\
\hline - Early $(I, I)$ & $24(19.2 \%)$ & NR & \multirow[t]{2}{*}{0.003} \\
\hline - Advanced (III, IV) & $101(80.8 \%)$ & 33.3 & \\
\hline \multicolumn{4}{|l|}{ Chemotherapy regimen: } \\
\hline - With paclitaxel & $113(90.4 \%)$ & 46.1 & \multirow[t]{2}{*}{0.035} \\
\hline - Without paclitaxel & $12(9.6 \%)$ & 16.6 & \\
\hline \multicolumn{4}{|l|}{ Chemotherapy regimen: } \\
\hline - With cisplatin & $55(44.0 \%)$ & 50.5 & \multirow[t]{2}{*}{0.24} \\
\hline - With carboplatin & $70(56.0 \%)$ & 32.3 & \\
\hline \multicolumn{4}{|l|}{ Type of histology: } \\
\hline - Serous & $68(54.4 \%)$ & 33.2 & \multirow[t]{2}{*}{0.047} \\
\hline - Other & $57(45.6 \%)$ & NR & \\
\hline \multicolumn{4}{|l|}{ Grading: } \\
\hline - 1 and 2 & $45(36.0 \%)$ & 49.8 & \multirow[t]{2}{*}{0.53} \\
\hline - 3 and unspecified & $80(64.0 \%)$ & 35.6 & \\
\hline \multicolumn{4}{|l|}{ Primary surgery: } \\
\hline - Optimal (<1 cm) & $77(61.6 \%)$ & 51.8 & \multirow[t]{2}{*}{0.028} \\
\hline - Suboptimal (>1 cm) & $48(38.4 \%)$ & 30.0 & \\
\hline \multicolumn{4}{|l|}{ BRCA1 status: } \\
\hline - Wild type & $108(86.4 \%)$ & 35.6 & \multirow[t]{2}{*}{0.041} \\
\hline - Germline mutation & $17(13.6 \%)$ & NR & \\
\hline \multicolumn{4}{|l|}{ Multivariate analysis } \\
\hline Variable & \multicolumn{2}{|l|}{$\mathrm{HR}(95 \% \mathrm{Cl})$} & $p$ value \\
\hline \multicolumn{4}{|l|}{ Age: } \\
\hline$<70$ & \multirow{2}{*}{\multicolumn{2}{|c|}{$0.15(0.053-0.417)$}} & \multirow[t]{2}{*}{$<0.001$} \\
\hline$\geq 70$ & & & \\
\hline \multicolumn{4}{|l|}{ Primary surgery: } \\
\hline - Optimal (<1 cm) & \multirow{2}{*}{\multicolumn{2}{|c|}{$0.39(0.205-0.715)$}} & \multirow[t]{2}{*}{0.003} \\
\hline - Suboptimal (>1 cm) & & & \\
\hline BRCA1 status: & & & \\
\hline - Germline mutation & $0.14(0.032-$ & 650) & 0.012 \\
\hline - Wild type & & & \\
\hline
\end{tabular}

NR not reached

changes and epigenetic alterations seem to have impact on detection of molecular abnormalities with clinical usefulness at a bed in oncology ward. TCGA (The Cancer Genome Atlas) project is a well-know initiative to establish a series of somatic mutations and epigenetic alterations in human cancer samples in relation to clinical data. Analyses performed in 489 ovarian cancer samples (mainly high-grade serous ovarian adenocarcinoma) revealed changes in expression of mRNA, noncoding RNA, methylation of promoter of many genes, and changed DNA copy numbers. The most important gene mutations were ascribed to P53 detected in $96 \%$ of investigated samples. Other low prevalent with statistical relevance aberrations in the form of somatic mutations were noted in such genes as NF1, BRCA1, BRCA2, RB1 and CDK12. In 168 genes, the authors detected promoter methylation alterations and prognosis for survival was performed in patients with BRCA mutations and CCNE1 aberrations [31].

Based on a cohort of 316 ovarian cancer patients taken from TCGA, $77.8 \%$ had BRCA1/2 wild type, $8.5 \%$ had germline mutations, $3.1 \%$ had somatic mutations, and 10.4 \% had BRCA1 hypermethylation. Detailed analyses showed that the only prognostic factor for OS in ovarian cancer was mutated BRCA2 (HR 0.33; 95 \% CI: 0.16-0.69, $p=0.003)$. Taking into account platinum-based chemotherapy efficacy, mutated BRCA2 gene had significantly longer PFS (HR 0.40; 95 \% CI: 0.22-0.74, $p=0.004$ ) [32]. Also, Hyman et al. [33] reported that better survival was seen in patients carrying BRCA2 mutations [HR 0.20; $95 \%$ CI 0.06-0.65, $p=0.007$ ] compared with either BRCA1 carriers [HR 0.70; $95 \%$ CI $0.36-1.38, p=0.31$ ] or noncarriers. The presented results are surprising, especially in the context of many published studies showing prognostic role of germline mutations of $B R C A 1$ gene. It seems that patient selection through a specific definition of primary response to adjuvant chemotherapy or variety in stage distribution will play a crucial role in the process of analysis and interpretation of collected results, but further studies should be planned as randomized and controlled with statistically well-founded number of participating patients. Some commentaries on the potential role of BRCA2 mutations as a real prognostic factor in ovarian cancer patients show such a particular role of patient selection and differences in surgical and oncologic managements [34].

\section{Conclusions}

To summarise, our findings confirm previous reports that improved overall survival associated with BRCA1 mutations carried in ovarian cancer patients. Both univariate and multivariate analyses show that the $B R C A$ gene status dychotomizes ovarian cancer patients to better and worse prognosis for overall survival (BRCA1 germline mutations constitute better prognosis than BRCA1 wild type). The most important limitation of our study is a small number of patients (125 patients, 17 with germline mutations of BRCA1 and 108 controls). Moreover, we focused only on three BRCA1 germline mutations typical for the Polish population that reflects 


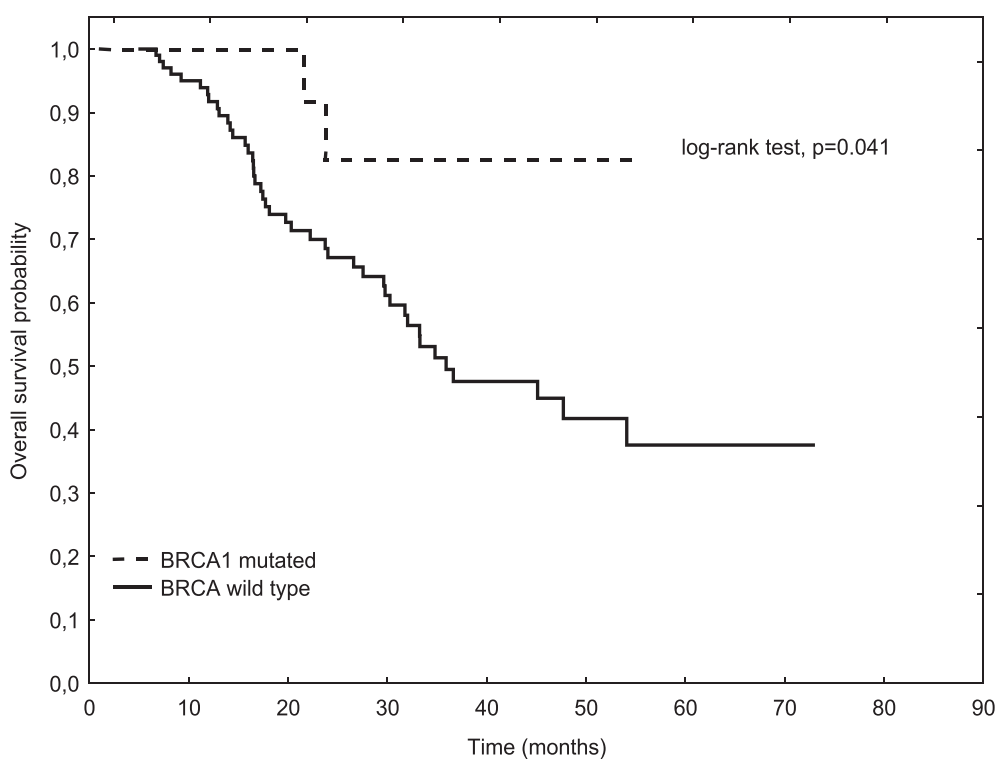

Fig. 1 Overall survival stratified by $B R C A 1$ status

low frequency such patients among consecutive patients visiting an oncologist. However, our results are consistent with other reports discussed above.

\section{Ethical statement}

The study was approved by the local Ethics Committee Military Institute of Medicine, Warsaw, Poland.

\section{Competing interests}

The authors declare that they have no competing interests.

\section{Authors' contributions}

AS conceived and designed the study, carried out molecular genetic studies, analysed, interpreted data, and drafted the manuscript. GW conceived and designed the study, analysed, interpreted data, and drafted the manuscript. LB participated in data collection and performed statistical analyses. BG designed molecular genetic studies. JS carried out molecular genetic studies. KSW participated in clinical data collection. CS participated in coordination and helped to draft the manuscript. All authors read and approved the final manuscript.

\section{Author details}

'Department of Oncology, Military Institute of Medicine, 128 Szaserow Str., 04-141 Warsaw, Poland. 'ㄹepartment of Genetics and Pathology,

Pomeranian Medical University, Szczecin, Poland.

Received: 8 October 2015 Accepted: 29 December 2015

Published online: 08 January 2016

\section{References}

1. Kerlikowske K, Brown JS, Grady DG. Should women with familial ovarian cancer undergo prophylactic oophorectomy? Obstet Gynecol. 1992;80:700-7.

2. Scully $R$, Livingston DM. In serach of the tumour-suppressor functions of BRCA1 and BRCA2. Nature. 2000:408:429-32.

3. Wooster R, Weber BL. Breast and ovarian cancer. N Engl J Med. 2003;348:2339-47.

4. Quinn JE, James CR, Stewart GE, Mulligan JM, White P, Chang GK, et al. BRCA1 mRNA expression levels predict for overall survival in ovarian cancer after chemotherapy. Clin Cancer Res. 2007:13:7413-20.

5. Jazaeri AA, Yee CJ, Sotiriou C, Brantley KR, Boyd J, Liu ET. Gene expression profiles of BRCA1-linked, BRCA2-linked, and sporadic ovarian cancers. J Natl Cancer Inst. 2002;94:990-1000.
6. Konstantinopoulos PA, Spentzos D, Karlan BY, Taniguchi T, Fountzilas E, Francoeur N, et al. Gene expression profile of BRCAness that correlates with responsiveness to chemotherapy and with outcome in patients with epithelial ovarian cancer. J Clin Oncol. 2010;28:3555-61.

7. Norquist B, Wurz KA, Pennil CC, Garcia R, Gross J, Sakai W, et al. Secondary somatic mutations restoring $B R C A 1 / 2$ predict chemotherapy resistance in hereditary ovarian carcinomas. J Clin Oncol. 2011;29:3008-15.

8. Wysham WZ, Mhawech-Fauceglia P, Li H, Hays L, Syria C, Skrepnik T, et al. $B R C$ Aness profile of sporadic ovarian cancer predicts disease recurrence. PLOS ONE. 2012;7(1):e30042. doi:10.1371/journal.pone.0030042.

9. Quinn JE, Carser JE, James CR, Kennedy RD, Harkin DP. BRCA1 and implications for response to chemotherapy in ovarian cancer. Gynecol Oncol. 2009;113:134-42.

10. Carser JE, Quinn JE, Michie CO, O'Brien EJ, McCluggage WG, Maxwell P, et al. BRCA1 is both a prognostic and predictive biomarker of response to chemotherapy in sporadic epithelial ovarian cancer. Gynecol Oncol. 2011;123: 492-8. doi:10.1016/j.ygyno.2011.08.017

11. Hirsh-Yechezkel G, Cherit A, Lubin F, Friedman E, Peretz P, Gershoni R, et al. Population attributes affecting the prevalence of BRCA mutation carriers in epithelial ovarian cancer cases in Israel. Gynecol Oncol. 2003:89:494-8.

12. Frank TS, Deffenbaugh AM, Reid JE, Hulick M, Ward BE, Lingenfolter B, et al. Clinical characteristics of individuals with germline mutations in BRCA1 and BRCA2: analysis of 10, 000 individuals. J Clin Oncol. 2002;20:1480-90.

13. Pal T, Permuth-Wey J, Kapoor R, Cantor A, Sutphen R. Improved survival in BRCA2 carriers with ovarian cancer. Fam Cancer. 2007:6:113-9.

14. Pharoah PD, Easton DF, Stockton DL, Gaither S, Ponder BA. Survival in familial, BRCA1-associated, and BRCA2-associated epithelial ovarian cancer. Cancer Res. 1999;59:868-71.

15. Johannsson OT, Ranstam J, Borg A, Olsson H. Survival of BRCA1 breast and ovarian cancer patients: a population-based study from southern Sweden. J Clin Oncol. 1998:16:397-404.

16. Narod SA, Moody J, Rosen B, Fan I, Risch A, Sun P, et al. Estimating survival rates after ovarian cancer among women tested for BRCA1 and BRCA2 mutations. Clin Genet. 2012 Jun 8;999(9999).doi 10.1111/j.1399-0004.2012.01906.X.

17. McLaughlin JR, Rosen B, Moody J, Pal T, Fun I, Shaw PA, et al. Long-term ovarian cancer survival associated with mutation in BRCA1 or BRCA2. J Natl Cancer Inst. 2013:105:141-8. doi:10.1093/inci/djs494.

18. Lahiri DK, Nurnberger Jr Jl. A rapid nonenzymatic method for the preparation of HMW DNA from blood for RFLP studies. Nucleic Acid Res. 1991:19:5444.

19. Górski B, Byrski T, Huzarski T, Jakubowska A, Menkiszak J, Gronwald J, et al. Founder mutations in the BRCA1 gene in Polish families with breast - ovarian cancer. Am J Hum Genet. 2000;66:1963-8.

20. Menkiszak J, Gronwald J, Górski B, Jakubowska A, Huzarski T, Byrski T, et al. Hereditary ovarian cancer in Poland. Int J Cancer. 2003;106:942-5. 
21. Brożek I, Ochman K, Dębniak J, Morzuch L, Ratajska M, Stepnowka M, et al. High frequency of BRCA1/2 germline mutations in consecutive ovarian cancer patients in Poland. Gynecol Oncol. 2008;108:433-7.

22. Rubin CS, Benjamin I, Behbakht K, Takahashi H, Morgan MA, LiVolsi VA, et al. Clinical and pathological features of ovarian cancer in women with germline mutations of BRCA1. N Engl J Med. 1996;335:1413-6.

23. Ben-David YB, Chetrit A, Hirsh-Yechezkel G, Friedman E, Beck BD, Beller V et al. Effect of BRCA mutations on the lenght of survival in epithelial ovarian tumors. J Clin Oncol. 2002;20:463-6.

24. Cass I, Baldwin RL, Varkey T, Moslehi R, Narod SA, Karlan BY, et al. Improved survival in women with BRCA-associated ovarian cancer. Cancer. 2003;97: 2187-95.

25. Tan DS, Rothermundt C, Thomas K, Bancroft E, Eeles R, Shanley S, et al. "BRCAness" syndrome in ovarian cancer: a case-control study describing the clinical features and outcome of patients with epithelial ovarian cancer associated with BRCA1 and BRCA2 mutations. J Clin Oncol. 2008;26:5530-6.

26. Turner N, Tutt A, Ashworth A. Hallmarks of "BRCAness" in sporadic cancer. Nat Rev Cancer. 2004;4:814-9.

27. Gallagher DJ, Konner JA, Bell-McGuinn KM, Bhatia J, Sabatini P, Aghajanian CA, et al. Survival in epithelial ovarian cancer: a multivariate analysis incorporating BRCA mutation status and platinum sensitivity. Ann Oncol. 2011:22:1127-32. doi:10.1093/annonc/mda577.

28. Thigpen T, Brady MF, Omura GA, Creasman WT, McGuire WP, Hoskins WJ, et al. Age as a prognostic factor in ovarian carcinoma. The Gynecologic Oncology Group experience. Cancer. 1993;71:606-14.

29. Gronlund B, Hogdall C, Hansen HH, Engelholm SA. Performance status rather than age is the key prognostic factor in second-line treatment of elderly patients with epithelial ovarian carcinoma. Cancer. 2002;94:1961-7.

30. Stratton MR, Campbell PJ, Futreal PA. The cancer genome. Nature. 2009;458:719-24. doi:10.1038/nature07943.

31. Cancer Genome Atlas Research Network. Integrated genomic analyses of ovarian carcinoma. Nature. 2011;474:609-15. doi:10.1038/nature10166.

32. Yang D, Khan S, Sun Y, Hess K, Shmulewich I, Sood AK, et al. Association of BRCA1 and BRCA2 mutations with survival, chemotherapy sensitivity, and gene mutator phenotype in patients with ovarian cancer. JAMA. 2011;306:1557-65.

33. Hyman DM, Zhou Q, lasonos A, Grisham RN, Arnold AG, Philips MF, et al. Improved survival for BRCA2-associated serous ovarian cancer compared with both BRCA-negative and BRCA1-associated serous ovarian cancer. Cancer. 2012;118:3703-9.

34. Buerkle $B$, Tempfer $C$. BRCA1 and BRCA2 mutations in ovarian cancer. JAMA. 2012;307:359. doi:10.1001/jama.2012.8.

\section{Submit your next manuscript to BioMed Central and we will help you at every step:}

- We accept pre-submission inquiries

- Our selector tool helps you to find the most relevant journal

- We provide round the clock customer support

- Convenient online submission

- Thorough peer review

- Inclusion in PubMed and all major indexing services

- Maximum visibility for your research

Submit your manuscript at www.biomedcentral.com/submit

C Biomed Central 